\title{
Human Survival vs. the Kantian Conception of the Self Reflections on Our Evolutionary Make-up
}

\author{
Laurence Thomas \\ Syracuse University
}

\begin{abstract}
As we all know, Immanuel Kant holds the view that human beings are quintessentially rational creatures; hence, the emotions are not much more than a form of excessive psychological baggage that human beings could do without. Indeed, for anyone familiar with the television series Star Trek, it would seem that according to Kant human beings bear a quite striking resemblance to the individual known as Spock who is a Vulcan and thus a completely rational creature who does not have emotions and feelings. For Kant, that is how human beings should be when they are at their very best as rational creatures. Interestingly, a question that mightily presents itself is whether or not evolution supports Kant's ideal conception of human beings as quintessentially rational creatures. It is quite clear that, unlike Vulcans, human beings are capable of emotions and feelings. Indeed, the capacity for emotions and feelings clearly constitutes a fundamental part of the biological make-up of human beings. With that reality, there are two primary ways we can go. On the one hand, we can hold that notwithstanding the capacity that human beings have for emotions and feelings, it is nonetheless the case that humans should mightily strive to realize the Kantian conception of the rational self. On the other hand, we can hold that the emotions and feelings play a very profound and fundamental role in the survival and self-realization of human beings. In what follows, I shall offer a number of considerations in support of the second line of thought; for in point of fact, the first option is not really an option given the psychological configuration of human beings.
\end{abstract}

Keywords: biological make-up, emotions, psychological make-up, rationality, fitting-in

\section{Human Affirmation}

What good are the emotions? To that question, there is a very simple and ever so sublime answer, namely that the emotions allow for a most majestic measure of affirmation and bonding; and these two psychological modes play a most significant role in human flourishing. From parental love to friendship and romantic love, the emotions play an absolutely indispensable role in the affirmation of the other. And part of the explanation for why the emotions play such a role is none other than the fact that we cannot choose the way we feel in the way that we can choose the words that we speak. Obviously, it takes no effort at all for an individual simply to utter to another the words "I love you," since those words can better uttered entirely at will. But clearly, it is another matter entirely to utter those very words with great emotional depth. And two indisputable facts are that

Laurence Thomas, professor, the Department of Philosophy and the Department of Political Science, Syracuse University, USA; main research field: Character, Friendship, Evolutionary Biology, and Moral Sensibilities. Email: lthomas@maxwell.syr.edu.

I am grateful to conversations about the arguments of this essay with three of my undergraduate students: Connor Hakan, Nathaniel Wilkens, and Michael Stikkel. 
(a) tremendous emotional depth cannot be produced at will and (b) human beings readily recognize when words are uttered with great emotional depth. ${ }^{1}$ Needless to say, (a) and (b) are equally important. For example, when the words "I love you," are uttered with emotional depth, those words constitute a most majestic measure of affirmation precisely because the person to whom those words are uttered recognizes the emotional depth with which they are uttered. This point holds whether we are talking about the utterance of those words by parents to their child, by one friend to another, or by one romantic partner to another.

The fact that even a child can recognize the emotional depth of the words "I love you" mightily speaks to the fact that human beings are biologically configured to offer and recognize emotional affirmation. For although upon birth an infant may not understand those words, it turns that out that within a few months after birth, an infant can grasp the deeply affirming emotional configuration with which her or his parents are uttering words "I love you;" and most significantly, the enfant is mightily affirmed by the manner in which those words are uttered to her or him.

It is obvious that the affirmation of parental love is fundamentally asymmetrical; and the child is the indisputable beneficiary of that love. Alas, a quite significant fact is that human beings go on to pursue two significant forms of symmetrical affirmation. One is the affirmation of friendship at its best. The other is the affirmation of a deep and abiding romantic bond. Another fact of tremendous importance is that human beings are biologically configured so as to never outgrow the need for affirmation.

Finally, there is a fourth form of emotional affirmation that may be referred to as social group affirmation (SGA). This is the affirmation that comes from being part of a group of individuals who share primarily the same basic values with respect to achieving goals and, in particular, leading a good life. It is with social group affirmation that we have what has been referred to in sociobiology as fitting-in. ${ }^{2}$ SGA does not require having personal ties in general with most members of the group. Rather, SGA is essentially tied to none other than the affirmation that comes from being recognized by various members of the group as embracing, and thus living a life, which embodies the key values of the group. The reason why SGA affirmation is so very important to human beings is that such affirmation plays a pivotal role in human survival, since a considerable amount of cooperation is needed among human beings in order for human beings to survive.

\section{Fitting-In and Group Identification}

It is clearly reasonable to hold that a measure of group identification exists among living creatures who are not human. For example, there is surely a measure of group identification among a herd of elephants, cattle, or lions, and so on. But among human beings, group identification is tied to a measure of acceptance and affirmation that simply has no equal among creatures who are not human beings. For it is only among human beings that there is the phenomenon of group pride, where individual members of the group are proud to be member of the group to which they belong rather than to some other group. With human beings, fitting-in is a fundamental part of the self-identity of the individuals—so much so that, with ever so rare exception, the members of the group can be counted upon to do their part even if they could easily get away with not doing so. Indeed, proudly displaying to other members of the group that one fits-in with the group often occasions a deep measure of affirmation from others.

The image on the next page of sagging pants stands as a very classic example of fitting-in. On the one hand, the drawback of wearing pants that are sagging that low is obvious. On the other hand, though, the benefit of young males fitting-in by wearing such sagging pants more than outweighs the drawback of wearing 
pants that are sagging that low. Such is the power of fitting-in. And as the example of sagging-pants reveal, it can turn out that exhibiting ridiculous behavior can prove to be a quite powerful way of fitting-in; precisely such behavior reveals the very depth of the person's commitment to being a part of the group in question.

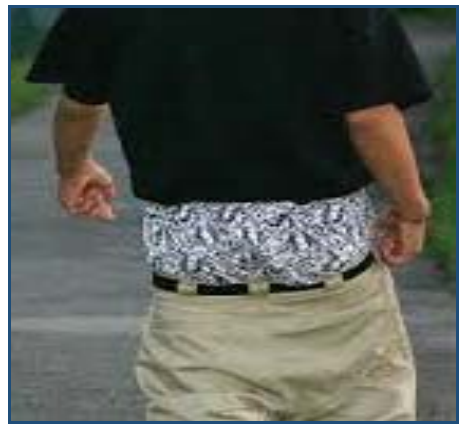

From an evolutionary perspective, there can be no denying the importance of social group affirmation (SGA) to the very survival of human beings precisely because a significant measure of genuine cooperation between human beings has always been absolutely key to the survival of any group of human beings. And fitting-in is one of the ways in which a person demonstrates to the relevant group of individuals the depth of her or his identification with the group and thus the reality that she or he can be counted upon by members of the group for genuine cooperation.

Most significantly, while a measure of rationality has certainly been essential to the survival of human beings, it is also the case that in a world replete with challenges (many of which are cannot be foreseen), an extraordinary measure of cooperation on the part of any group of individuals has been absolutely crucial to the survival of that group.

In his famous article "Persons, Character and Morality," Bernard Williams introduces the idea of having "one thought too many,"3 a point which is illustrated with the example of saving the life of a spouse. If, for instance, a married person on land sees that her or his spouse is drowning, what is surely not the case, so Williams holds, is that the spouse on land should give a lot of thought to what should be done. Au contraire, so Williams argues, upon seeing that the spouse is drowning, the spouse on land should immediately be in the in throes of doing something in order to save the life of the spouse who is drowning.

Throughout human history, there have been countless challenges to human survival that have required an immediate response on the part of the group of individuals whose survival is threatened. Needless to say, fitting-in has played an absolutely key role in the members of the group being able to diffuse the threat successfully. Although fitting-in is not as crucial to sheer human survival as it once was, it remains the case that fitting-in continues to plays a quite fundamental role among human beings. This is because humans are not even close to having the psychological configuration of a creature such as a Vulcan for whom sheer rational thought is all that matters. In particular, the need for affirmation continues to be a fundamental part of the psychological make-up of human beings; and with rare exception fitting-in continues to be the conduit for attaining that affirmation.

\section{Moral Courage in the Face of the Spector of Evil}

I should like to conclude this essay by bringing out how the account of the human self that has been presented provides a considerable measure of insight into human beings engaging in evil behavior. ${ }^{4}$ Quite simply, so very much evil that has occurred in the world would not have occurred not for the reality that 
fitting-in is a rather significant aspect of human survival. With physical harm, for example, there is a very straightforward sense in which it is very, very difficult—perhaps even impossible in most cases—for a mentally competent human being not to grasp that another human being is being subjected to tremendous physical harm, given that the harm is being witnessed as it occurs. Yet, how the individual morally characterizes the harm—say, as either excusable or justified, on the one hand, or ever so morally inappropriate, on the other - can be very much tied to the group with whom the individual is fundamentally committed to fitting-in. Indeed, a most poignant reality is that it can be very much to an individual's advantage to embrace the view that is being embraced by the group at-large; otherwise, the individual is apt to face wide-spread disapproval from group members. Even worse, the individual might face outright rejection.

Invoking what is known as inference to the best explanation, Kant's own view of the intellectual inferiority of various groups in comparison to the citizens of his country can be explained in the way indicated in the preceding paragraph. In effect, Kant embraced the prevailing view of the citizens of his country regarding the intellectual and moral inferiority of some groups of people $;^{5}$ and in so doing, he secured his standing with his fellow citizens. Kant embraced the prevailing view just mentioned although he had quite ample evidence that many of his fellow citizens were surely no more intellectually capable than the people whom he presumed to be inferior. Invoking what is known as inference to the best explanation, Kant rendered more secure his standing among his fellow citizens by embracing the widespread view that certain other peoples were intellectually and morally inferior. In other words, Kant made a point of fitting-in with his fellow citizens with respect to a matter of fundamental importance to their social identity. In this regard, it must be noted that one of the most intriguing features of human beings is the capacity for self-deception.

The above considerations bring out just how significant moral courage is in combating evil on the part of the social group to which we belong and which has been a profoundly significant source of affirmation in our life. More often than not, the psychological reality is that the courage to stand up to the group is trumped by affirmation that we receive from the group. And that reality has considerable explanatory power, not the least of which is the self-deception that people engage in order to fit-in with the group in question.

To be sure, the issue is not whether courage is a virtue. Of course, it is. But that truth does not negate the reality that a person's standing up to the wrongdoing that is being committed by those who have been a fundamental source of affirmation in her or his life comes at a considerable price. Needless to say, the point here is not to excuse evil but to shed light on the psychology that is involved in standing up to evil owing to the psychological configuration of fitting-in that has had enormous survival value among human beings. Put another way, combating evil is inextricably tied to grasping the very nature of its grip.

No doubt it might seem that with the preceding remarks, evil is being excused. Not so, however. There should be no justification for excusing evil. Yet, a most poignant truth is that we will never defeat evil if we do not understand how it comes to have such an extraordinary grip upon people, namely via the significance of fitting-in that is a fundamental part of the biological make-up of human beings. Indeed, the irony of ironies is that we mightily deceive ourselves if we ignore the enormous importance that fitting-in has to the human psyche. The scenario mentioned above of the sagging pants is a most powerful example in that regard. For the only benefit to wearing such sagging pants is that of fitting-in. Yet, that benefit is deemed to be worth the considerable awkwardness of wearing such pants. At this point in the history of humanity, there is a benefit in terms of that comes with fitting-in that, with rare exception, so very many human beings have difficulty declining. Accordingly, a very important reality is that combating a significant form of evil, namely that 
committed by groups, is inextricably tied to diffusing the character and type of fitting-in that presently means so very much to the vast majority of human beings. So it is not withstanding all the talk about being independent and autonomous. From an evolutionary perspective, this should not come as a surprise given how crucial fitting-in has been to the very survival of human beings since the very beginning of humanity.

\section{Notes}

1. To be sure, a good actor can display anguish or joy as is required by the role the person is playing. But getting that display of emotion just right requires considerable practice.

2. William von Hippel and Robert Trivers, "The Evolution and Psychology of Self-Deception,” Behavioral and Brain Sciences 34 (2011), 1-56 and Robert Trivers, "Self-Deception in Service of Deceit," Natural Selection and Social Theory (New York: Oxford University Press, 2002), 255-62; and The Folly of Fools: The Logic of Self-Deception in Human Life (New York: Basic Books, 2011), especially chapter 7, "The Psychology of Self-Deception.”

3. Bernard Williams, Moral Luck: Philosophical Papers: 1973-1980 (Cambridge University Press, 1981).

4. In writing this section, I am much indebted to the work Serge Bilé and Raphael Lagier. Bilé gives a most interesting account of whites as slaves in Africa.

5. Kant's Observations on the Feelings of the Beautiful and the Sublime.

\section{Works Cited}

Bilé, Serge. Quand Les Noirs Avaient des Esclaves Blancs. Saint-Malo, Pascal Galodé, 2008.

Lagier, Raphiel. Les Races Humaines Selon Kant. Paris: Presses Universitaires de France, 2004.

Williams, Bernard. Moral Luck: Philosophical Papers: 1973-1980. Cambridge: Cambridge University Press, 1981.

Robert, Trivers. "Self-Deception in Service of Deceit.” Natural Selection and Social Theory. New York: Oxford University Press, 2002. 255-62.

---. “The Psychology of Self-Deception.” The Folly of Fools: The Logic of Self-Deception in Human Life. New York: Basic Books, 2011. Ch. 7.

William, von Hippel and Robert Trivers. “The Evolution and Psychology of Self-Deception.” Behavioral and Brain Sciences 34 (2011): 1-56 